\title{
Multimodal Quantitative Magnetic Resonance Imaging of Thalamic Development and Aging across the Human Lifespan: Implications to Neurodegeneration in Multiple Sclerosis
}

\author{
Khader M. Hasan, ${ }^{1}$ Indika S. Walimuni, ${ }^{1}$ Humaira Abid, ${ }^{1}$ Richard E. Frye, ${ }^{2}$ Linda Ewing-Cobbs, ${ }^{2}$ Jerry S. Wolinsky, ${ }^{3}$ \\ and Ponnada A. Narayana ${ }^{1}$ \\ Departments of ${ }^{1}$ Diagnostic \& Interventional Imaging, ${ }^{2}$ Pediatrics, and ${ }^{3}$ Neurology, The University of Texas Health Science Center at Houston, Houston, \\ Texas 77030
}

The human brain thalami play essential roles in integrating cognitive, sensory, and motor functions. In multiple sclerosis (MS), quantitative magnetic resonance imaging (qMRI) measurements of the thalami provide important biomarkers of disease progression, but late development and aging confound the interpretation of data collected from patients over a wide age range. Thalamic tissue volume loss due to natural aging and its interplay with lesion-driven pathology has not been investigated previously. In this work, we used standardized thalamic volumetry combined with diffusion tensor imaging, T2 relaxometry, and lesion mapping on large cohorts of controls $(N=$ 255 , age range $=6.2-69.1$ years $)$ and MS patients $(N=109$, age range $=20.8-68.5$ years $)$ to demonstrate early age- and lesionindependent thalamic neurodegeneration.

\section{Introduction}

The thalamus is composed of complex gray matter (GM) nuclei interconnected with white matter (WM) fascicles and provides an essential relay to the cortex, striatum, brainstem, and cerebellum (Behrens et al., 2003). Postmortem studies on multiple sclerosis (MS) patients indicated atrophic thalami with reduced neuronal density (Cifelli et al., 2002; Vercellino et al., 2009). Several in vivo studies have shown abnormal thalami in MS using different quantitative neuroimaging methods, including glucose metabolism (Blinkenberg et al., 2000; Derache et al., 2006), voxel-based morphometry (Ceccarelli et al., 2008; Tao et al., 2009), manual delineation (Houtchens et al., 2007; Rocca et al., 2010), automated atlas-based volumetry (Ramasamy et al., 2009; Pellicano et al., 2010), spectroscopy (Cifelli et al., 2002; Geurts et al., 2006), perfusion (Varga et al., 2009), relaxometry (Niepel et al., 2006), iron-mapping methods (Ge et al., 2007), diffusion ten-

Received Aug. 13, 2011; revised Sept. 29, 2011; accepted 0ct. 6, 2011.

Author contributions: K.M.H., R.E.F., L.E.-C.,J.S.W., and P.A.N. designed research;K.M.H.,I.S.W., H.A., J.S.W., and P.A.N. performed research; K.M.H., R.E.F., L.E.-C., J.S.W., and P.A.N. contributed unpublished reagents/analytic tools; K.M.H., I.S.W., H.A., and R.E.F. analyzed data; K.M.H., I.S.W., H.A., R.E.F., L.E.-C., J.S.W., and P.A.N. wrote the paper.

This work is funded by the National Institutes of Health (NIH/NINDS R01-NS052505-04) and the Dunn Research Fund to K.M.H., NIH/NIBIB EB002095 to P.A.N., an unrestricted gift from the Band Against Multiple Sclerosis to J.S.W., NS046565 to R.E.F., and R01 NS046308 awarded to L.E.-C. The purchase of the 3.0 T MRI Clinical Scanner was partially funded by NIH Grant S10 RR19186 to P.A.N. We thank Vipul Kumar Patel for helping in data acquisition.

The authors declare no competing financial interests.

Correspondence should be addressed to Dr. Khader M. Hasan, Department of Diagnostic \& Interventional Imaging, The University of Texas Health Science Center at Houston, 6431 Fannin Street MSB 2.100, Houston TX 77030. E-mail: Khader.M.Hasan@uth.tmc.edu.

DOI:10.1523/JNEUROSCI.4184-11.2011

Copyright $\odot 2011$ the authors $\quad 0270-6474 / 11 / 3116826-07 \$ 15.00 / 0$ sor imaging (DTI) (Tovar-Moll et al., 2009), and DTI-based fiber tractography (Henry et al., 2009) Thalamic atrophy has been reported in children diagnosed with MS (Mesaros et al., 2008; Aubert-Broche et al., 2011), clinically isolated syndrome (CIS) indicative of MS (Henry et al., 2009), and adult phenotypes of MS, including relapsing-remitting (RRMS), secondaryprogressive (SPMS), and primary progressive MS (Ceccarelli et al., 2008; Rocca et al., 2010). In MS, reduced thalamic volume and hypometabolism were implicated in fatigue (Pellicano et al., 2010), cognitive dysfunction (Derache et al., 2006), and physical disability (Niepel et al., 2006). Thalamic lesions have been reported to be rare in RRMS using in vivo MRI (Bagnato et al., 2006; Derache et al., 2006; Tovar-Moll et al., 2009). However, thalamic lesions have been reported to be more visible using advanced histopathological methods (Vercellino et al., 2009).

In the absence of visible lesions, thalamic neuronal loss can be attributed to extrinsic and intrinsic factors (Cifelli et al., 2002; Henry et al., 2009; Sepulcre et al., 2009; Vercellino et al., 2009). Extrinsic factors are related to remote lesion activity in connected regions (e.g., anterograde degeneration in optic nerve and retrograde effects of lesions in brainstem, spinal cord, cerebellar, or cerebral WM). Intrinsic factors relate to the possible effects of microscopic inflammatory lesions within internuclear thalamic WM not visible on MRI, which could lead eventually to thalamocortical neuronal loss (Cifelli et al., 2002; Sepulcre et al., 2009; Vercellino et al., 2009).

The thalamus volume increases in typically developing children (Ostby et al., 2009) and decreases in healthy adults (Walhovd et al., 2011). Accounting for the late development and natural aging of the thalamus is important to help interpret the 
Table 1. Basic demographics, clinical, MRI-based whole brain lesion volume and normalized thalamic volume information on healthy children, adult controls and the three patient groups

\begin{tabular}{|c|c|c|c|c|c|}
\hline & \multicolumn{2}{|l|}{ Controls } & \multicolumn{3}{|l|}{ Patients } \\
\hline & Child & Adult & CIS & RRMS & SPMS \\
\hline$N(\mathrm{~F})$ & $126(49)$ & $129(69)$ & $9(7)$ & $88(68)$ & $12(7)$ \\
\hline (\%Females) & $(39 \%)$ & $(54 \%)$ & $(78 \%)$ & $(77 \%)$ & $(58 \%)$ \\
\hline \multicolumn{6}{|l|}{ Age (years) } \\
\hline Mean \pm SD & $12.2 \pm 3.8$ & $36.0 \pm 11.3$ & $39.2 \pm 14.7$ & $42.6 \pm 9.8$ & $54.7 \pm 9.6$ \\
\hline Median & 11.3 & 34.0 & 40.2 & 44.7 & 56.1 \\
\hline \multirow[t]{3}{*}{ [Range] } & {$[6.2-20.7]$} & {$[20.8-69.1]$} & {$[20.8-50.6]$} & {$[22.0-63.1]$} & {$[35.4-68.5]$} \\
\hline & & & $2.8 \pm 3.2$ & $11.1 \pm 9.2$ & $18.6 \pm 9.6$ \\
\hline & & & 1.3 & 10.1 & 18.9 \\
\hline \multirow[t]{3}{*}{ EDSS } & Not applicable & & {$[0.2-8.8]$} & {$[0.1-36.8]$} & {$[1.8-33.4]$} \\
\hline & & & $0.4 \pm 0.8$ & $1.7 \pm 1.6$ & $4.2 \pm 1.3$ \\
\hline & & & 0 & 1.5 & 4 \\
\hline \multirow[t]{3}{*}{ Disease duration (years) } & Not applicable & & {$[0-2]$} & {$[0-6.5]$} & {$[2-6]$} \\
\hline & & & $2.21 \pm 2.74$ & $12.23 \pm 11.69$ & $22.31 \pm 9.70$ \\
\hline & & & 1.34 & 7.26 & 26.84 \\
\hline Whole-brain lesion volume (ml) & No lesions & & {$[0.15-8.16]$} & $0.18-44.79$ & {$[6.98-37.27]$} \\
\hline NTV & $1.09 \pm 0.11$ & $1.03 \pm 0.10$ & $1.00 \pm 0.07$ & $0.92 \pm 0.11$ & $0.82 \pm 0.09$ \\
\hline
\end{tabular}
$0.03 ; p$ NTV $($ CIS $\sim$ adult controls $)=0.36 ; p$ NTV (healthy children $>$ adults $)<1 \times 10^{-4}$.

findings in MS in particular when MS patients include young adults. There has been no comprehensive in vivo report across the healthy human lifespan on the volumetry and microstructural attributes of the normal-appearing thalami relative to a large cohort of young and aging MS patients. The availability of such baseline data would help model the contributors to the pathogenesis of MS.

In this work, we hypothesized that the thalamus proper volume and its corresponding quantitative magnetic resonance imaging (qMRI) microstructural attributes can mark the lesiondriven atrophy relative to a neurodegenerative component that is independent of age and total brain lesion volume (LV). To accomplish this goal, we used standardized and multimodal qMRI that included transverse magnetization relaxation time (T2) and DTI (Pierpaoli et al., 1996) combined with lesion-mapping methods on a large cohort of healthy controls aged 6-69 years to interpret data collected from a substantial cohort of CIS, RRMS, and SPMS patients.

\section{Materials and Methods}

Study population. The MRI protocol was approved by our Institutional Review Board. Written informed consent was obtained from all subjects or their guardians in the case of healthy children. Table 1 provides a detailed account of the demographics, clinical, and whole-brain lesion information on all subjects. In brief, we included 109 patients $(75 \%$ females; 9 CIS, 88 RRMS, and 12 SPMS), aged 20.8-68.5 years, with a disease duration (DD) of 0.1-36.8 years and expanded disability status score (EDSS) from 0 to 6.5. At the time of their imaging session, $47 \%$ of patients were using glatiramer acetate, $\sim 22 \%$ an interferon $\beta$ preparation $(73.7 \%$ a subcutaneous product), and $\sim 25 \%$ were not on any disease modifying therapy. In addition, 255 healthy controls $(46.3 \%$ females) aged 6.2-69.1 years were recruited from the local community and university staff. The healthy controls included 126 children $(39 \%$ girls) aged 6.2-20.7 years and 129 adults (54\% women) aged 20.8-69.1 years. The healthy children were recruited as part of ongoing clinical studies using identical MRI data acquisition protocols. All control subjects were screened for history of head trauma, surgery, chronic illness, alcohol, and/or drug abuse, neurological illness, and current pregnancy. None of the controls in this study reported any neurological conditions and their fluid-attenuated inversion recovery (FLAIR) images were judged to be normal by a board certified radiologist.

MRI data acquisition. All MRI studies were performed on a $3.0 \mathrm{~T}$ Philips Intera scanner with a dual quasar gradient system with maximum gradient amplitude of $80 \mathrm{mT} / \mathrm{m}$ and an eight channel SENSE-compatible head coil (Philips Medical Systems). MRI data collected on each subject included three-dimensional T1-weighted anatomical, two-dimensional DTI data (Hasan and Narayana, 2003) along with dual fast spin-echo (FSE) and FLAIR for lesion localization and quantification (Sajja et al., 2006).

MRI data processing. The T1-weighted and T2-weighted volumes were masked to remove nonbrain tissues (Smith, 2002). The intracranial volume (ICV) was computed from the T2-weighted volumes and included both ventricular and sulcal CSF as described previously (Courchesne et al., 2000; Hasan et al., 2007). The T1-weighted volumes were prepared for subsequent processing, segmentation, and anatomical labeling using FreeSurfer (Fischl et al., 2002; Desikan et al., 2006) (http://surfer.nmr. mgh.harvard.edu/fswiki/FreeSurferWiki). The application and validation of FreeSurfer to MS brain tissue segmentation and atlas labeling has been detailed in several reports (Sailer et al., 2003; Ramasamy et al., 2009; Derakhshan et al., 2010). The T2 relaxation time (Hasan et al., 2010, 2011a) and diffusion tensor metrics were estimated from each anatomical region as detailed previously (Walimuni and Hasan, 2011).

Lesion volume segmentation and lesion probability map estimation. Whole-brain lesion volume (LV) was quantified in the patient groups using the coregistered dual FSE and FLAIR volumes (Sajja et al., 2006; Hasan et al., 2009; Tao et al., 2009). After inspection by a trained rater, the lesion volume maps were saved as binary masks to enable fusion with other multimodal volumes acquired from the same subject (Brett et al., 2001). Lesion probability maps were generated as described previously (Narayanan et al., 1997; Ceccarelli et al., 2008). The lesion and qMRI maps were visualized and fused with MRIcroN (http://www.nitrc.org/projects/mricron/).

Multimodal MRI data fusion. All MRI-derived volumes (i.e., T2, lesion masks) and DTI-derived volumes (i.e., fractional anisotropy, mean, radial, and axial diffusivities) were coregistered to the T1-weighted volume. Lesion masks were used to null out lesions from the atlas-based volume results (Brett et al., 2001; Ceccarelli et al., 2008; Aubert-Broche et al., 2011).

Scanner stability and data quality assurance. The MRI data used in this report were collected over $\sim 5$ year span during which scanner stability, intrascan and interscan reliability, and reproducibility were monitored closely using a database of water phantom relaxation time and DTI measurements (Hasan, 2007) and brain data acquired serially on healthy children (Hasan et al., 2011b), healthy adults (Hasan et al., 2007; Hasan and Frye, 2011), and MS patients (Hasan et al., 2009). The age-expected volume of regional WM tracts, subcortical GM, and whole-brain tissue have been reported previously on $\sim 60 \%$ of all healthy children and 

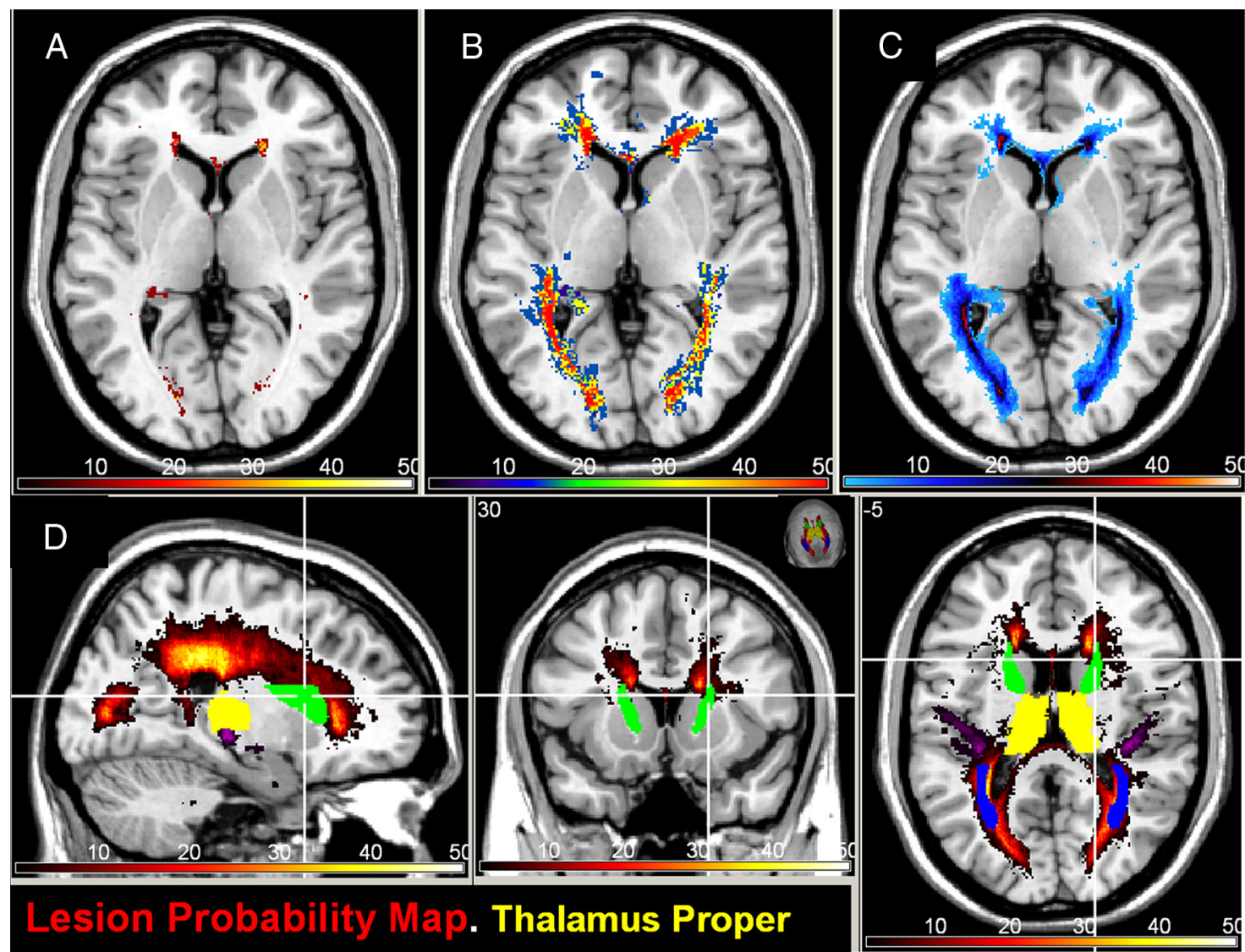

Anterior, Auditory, Posterior Thalamic Radiations

Figure 1. Spatial distribution of lesions or lesion probability map viewed in standard Montreal Neurological Institute (MNI) space on CIS (A), SPMS (B), and RRMS (C, D). Note the areas of high lesion frequency (posterior corona radiata, optic radiations) and regions with low lesions (e.g., thalamus proper).

adults included in this report (Hasan et al., 2007, 2010a,b; Hasan and Frye, 2011). The age-expected global or regional volumetry and their corresponding microstructural attributes obtained on healthy children, adults and across the lifespan were consistent with data published by others (Courchesne et al., 2000; Sowell et al., 2003; Lebel et al., 2008; Leppert et al., 2009; Ostby et al., 2009; Saito et al., 2009; Kochunov et al., 2010; Walhovd et al., 2011). The brain MRI data of all controls included in this report were void of lesions. MS lesions and segmented volume boundaries were fused and inspected by trained raters.

Statistical analysis. Given several reports on minute gender or hemispheric effects compared to pathology and age (Fjell et al., 2009; Hasan et al., 2009; Ostby et al., 2009; Walhovd et al., 2011), we pooled the measurements from both left and right thalami. Since we used data from healthy children, young and older adults, it was essential to fit the normalized thalami volume as a function of age using a combination of linear, quadratic, or cubic coefficients (Hasan et al., 2010a,b; Walhovd et al., 2011). Generalized linear models and goodness-of-fit methods were used to estimate the best fit parameters and their corresponding standard errors (Hasan et al., 2010a,b). In patients the correlations between age, normalized thalamic volumes (NTV), and whole-brain LV, disease duration, and T2 values and DTI-derived metrics were computed using the Pearson correlation coefficient. Age-adjusted correlations between EDSS score and all other qMRI variables were computed using the Spearman coefficient and analysis of covariance. Slopes and rates of change of MRI metrics with age were compared using the $r$-to- $z$ Fisher transform. Comparisons between group means and medians were performed using ANOVA ( $t$ test or $F=t^{2}$ ) and the Mann-Whitney $U$ test. All group qMRI comparison differences and statistical significance were computed volumewise in native data space and were presented in standard space for visual inspection and fusion with the lesion probability maps. All statis- tical analyses used MATLAB R12.1 Statistical Toolbox v 3.0 (The MathWorks).

\section{Results}

Population demographics and clinical information

Healthy boys and girls, men, and women or males and females did not differ in age $(p>0.1)$. Despite differences in age range, the CIS and RRMS groups were comparable in mean age $(p=$ 0.3 ), whereas the SPMS group was older than the RRMS $(p=3 \times$ $\left.10^{-5}\right)$. On the entire patient population, significant correlations were noted between age, DD, LV, and EDSS: $r$ (age, EDSS) $=0.34$ $\left(p=3 \times 10^{-4}\right), r($ age, $\mathrm{DD})=0.57\left(p=1 \times 10^{-10}\right), r($ age, $\mathrm{LV})=$ $0.19(p=0.04), r(\mathrm{DD}, \mathrm{EDSS})=0.48\left(p=1 \times 10^{-7}\right), r(\mathrm{LV}$, EDSS $)=0.50\left(p=3 \times 10^{-8}\right)$, and $r(\mathrm{LV}, \mathrm{DD})=0.31(p=0.001)$.

\section{Visualization of lesions in patients}

Figure $1 A$ shows the lesion probability map on the CIS, SPMS (Fig. $1 B$ ), and RRMS (Fig. 1C) patients at a selected level highlighting the anterior, middle, and posterior thalamocortical connections. Figure $1 D$ highlights the regions with the highest lesion frequency in the RRMS patients such as the posterior corona radiata and optic radiations. In all MS phenotypes, lesions were least frequent in the thalamus proper, amygdalae, putamen, and cerebellar GM (Fig. 1).

Widespread loss of tissue volume or macrostructure and changes in microstructure in the RRMS cohort have been reported previously (Hasan et al., 2011c,d). In this report and the analyses below, we only focused on the normal-appearing thalamus proper to help identify markers of tissue injury in MS. 
A $\square r_{p}(p, n)=-0.311(3.9 e-007,255) \& y_{f}=(1.116 \pm 0.013)-(0.002 \pm 0.000)^{*} \times$ (Controls) - $r_{p}(p, n)=-0.297(0.002,109) \& y_{f}=(1.055 \pm 0.046)-(0.003 \pm 0.001)^{*} \times(M S)-$ - cubic $(x 1000)$
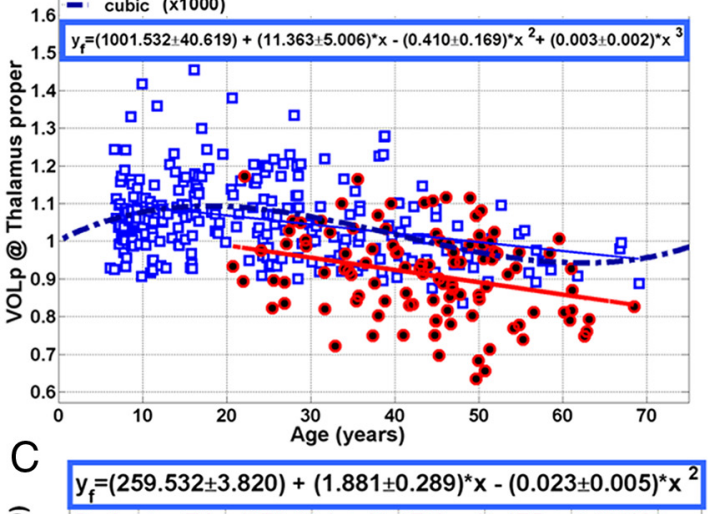

ठิ Patients: FA $=(278.924 \pm 10.273)+(0.175 \pm 0.230)^{*}$ Age $\check{\check{x}}^{360} \mathrm{r}=0.076(0.45)$

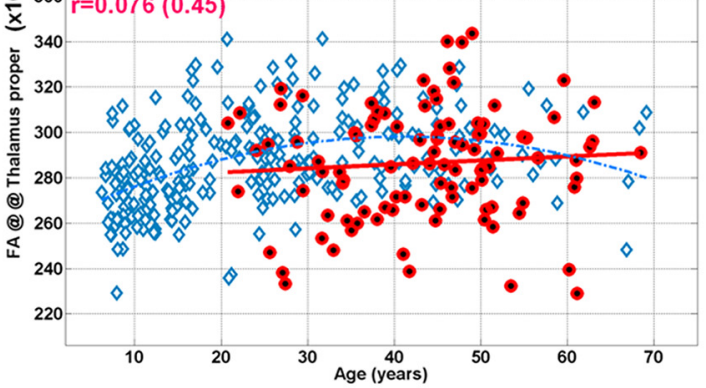

E

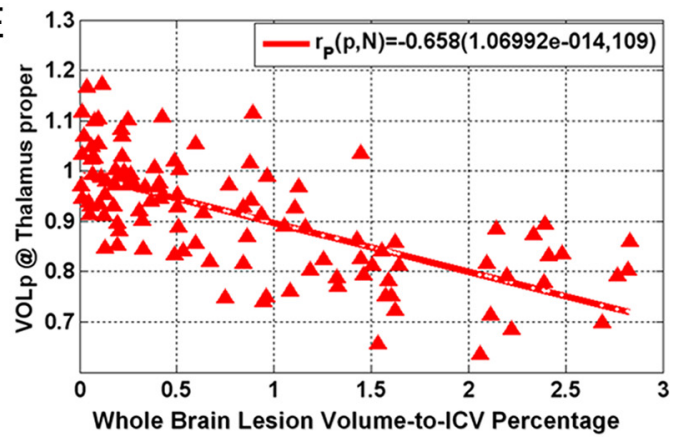

B

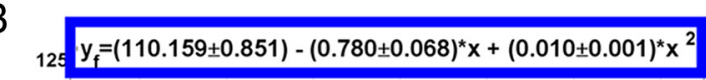

¿ू 120 - Patients: T2 $=(91.136 \pm 1.840)+(0.138 \pm 0.041)^{*}$ Age 115. $r=0.316(0.001)$
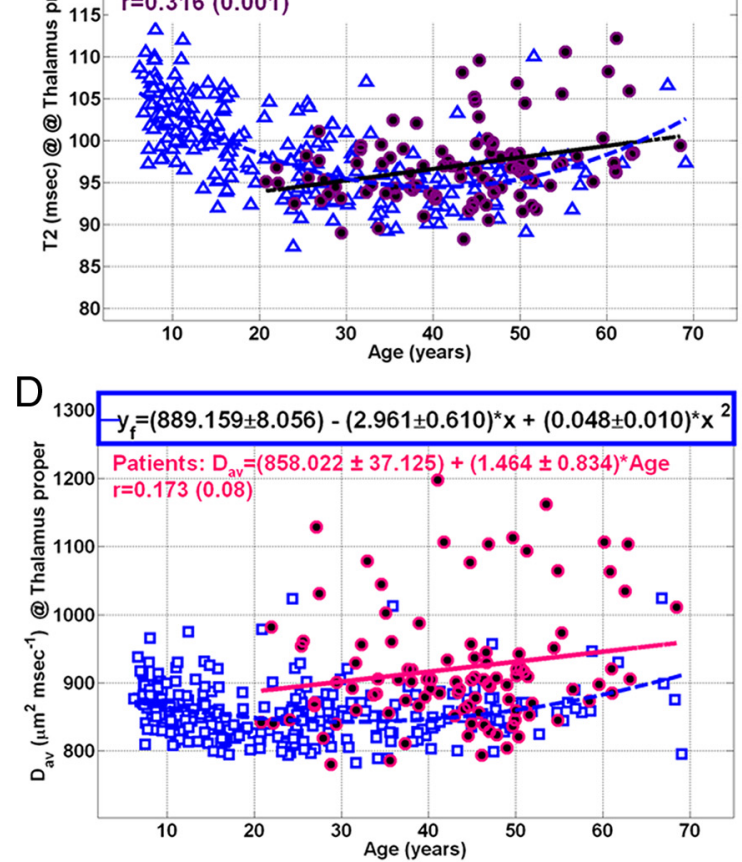

$r_{s}(p, N)=-0.201(0.038,109)$ (Adjusted for age \& LVp)

F

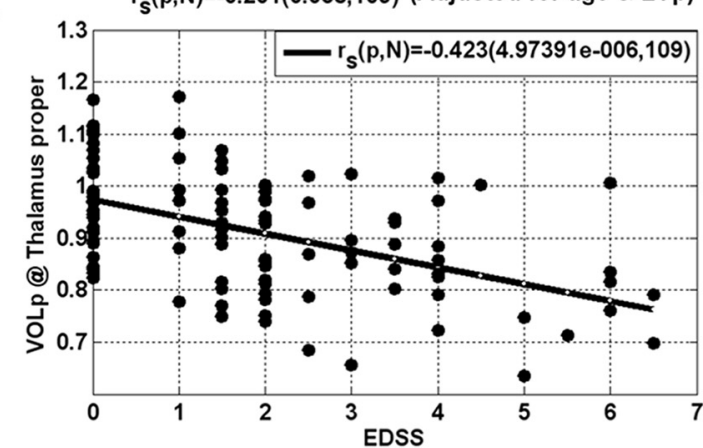

Figure 2. Representative illustration and analysis of age dependence of thalamic qMRI metrics in all controls and patients using scatter plots and linear regression. $\boldsymbol{A}-\boldsymbol{D}$, Volume percentage of the thalamus proper $(\boldsymbol{A})$ and corresponding $T 2$ relaxation time values $(\boldsymbol{B})$, fractional anisotropy $(\times 1000.0)(\boldsymbol{C})$, and mean or average diffusivity $\left(D_{\text {av }}\right)(\boldsymbol{D})$. Note the rise in normalized thalamic volume in healthy children and consequent rapid decrease in both healthy adults and patients. Note the curvilinear age-expected thalamic volumes in healthy controls. $\boldsymbol{E}, \boldsymbol{F}$, The variation of thalamic volume percentage with whole-brain lesion volume-to-ICV percentage $(\operatorname{LV})(\boldsymbol{E})$ and the scatter and regression of NTV with EDSS $(\boldsymbol{F})$.

Group differences in thalamic volumetry

To minimize the effects of brain size variability between males and females, the ICV was used to normalize the thalamic volume measurements (Courchesne et al., 2000; Cifelli et al., 2002; Pellicano et al., 2010). The normal-appearing NTV or percentage of total thalamic proper volume-to-ICV $($ VOLp $=$ VOL/ICV $\times 100 \%)$ was larger in healthy children than in adult controls $\left(p=1 \times 10^{-4}\right)$. The NTV was comparable between adult controls and CIS $(p=0.36)$. The NTV was larger in CIS than in RRMS $(p=0.03)$. The NTV was larger in adult controls than in RRMS $\left(p=4.8 \times 10^{-13}\right)$ and larger in adult controls than in SPMS $\left(p=1 \times 10^{-10} ; \sim 20 \%\right)$.

Thalamic volumetry in healthy children and adults

The NTV increased with age in healthy children: NTV(Age) $=$ $(1.012 \pm 0.033)+(0.006 \pm 0.003) \times$ Age $(r=0.205 ; p=0.021$; $N=126)$, whereas in adult controls, the NTV decreased with age: $\mathrm{NTV}($ Age $)=(1.161 \pm 0.028)-(0.004 \pm 0.001) \times$ Age $(r=$ $\left.-0.391 ; p=4.5 \times 10^{-6} ; N=129\right)$.
Thalamic qMRI metrics of healthy controls across the lifespan and MS patients

Figure $2 A-D$ shows the thalamic volume percentage (Fig. $2 A$ ) and corresponding T2 relaxation time (Fig. $2 B$ ), fractional anisotropy (FA) (Fig. 2C), and average or mean diffusivity (Fig. 2D) as age advances on controls and patients. Note the rise, plateau, and fall of qMRI metrics upon pooling all healthy controls reflecting expected changes in tissue microstructure. In healthy controls, curvilinear age effects on T2, mean diffusivity, and FA are significant even without using the children data, which were more crucial to capturing the age-expected NTV. Compared to adult controls, note that the NTV is reduced in patients $\left(p<10^{-14}\right)$ along with elevated T2, reduced $\mathrm{FA}$, and elevated tensor diffusivities.

Thalamic qMRI metrics variation with age, DD, LV, and EDSS in MS

Table 2 summarizes the correlations of thalamic qMRI metrics in patients with age $[$ Fig. $2 A ; \mathrm{NTV}($ Age in years $)=(1.05 \pm 0.046)-$ 
Table 2. Correlation coefficient and statistical significance of the average normal-appearing thalamic qMRI metrics with age, disease duration, whole-brain LV, and EDSS in the 109 patients

\begin{tabular}{|c|c|c|c|c|c|}
\hline qMRI & Age & $\operatorname{DD} r(p)$ & $\begin{array}{l}\mathrm{LV} \\
r(p)\end{array}$ & $\begin{array}{l}\text { EDSS } \\
r(p)\end{array}$ & $\begin{array}{l}\text { EDSS-covaried } \\
\text { (age \& LV) } r(p)\end{array}$ \\
\hline VOLp & $\begin{array}{l}-0.297 \\
\mathbf{( 0 . 0 0 2 )}\end{array}$ & $\begin{array}{l}-0.257 \\
(\mathbf{0 . 0 0 7 )}\end{array}$ & $\begin{array}{l}-0.658 \\
\left(1.07 \times 10^{-14)}\right.\end{array}$ & $\begin{array}{l}-0.423 \\
\left(5 \times 10^{-6}\right)\end{array}$ & $\begin{array}{l}-0.20 \\
(\mathbf{0 . 0 4 )}\end{array}$ \\
\hline $\mathrm{T} 2$ & $\begin{array}{r}0.316 \\
(\mathbf{0 . 0 0 1 )}\end{array}$ & $\begin{array}{r}0.285 \\
(0.004)\end{array}$ & $\begin{array}{l}0.45 \\
\left(2 \times 10^{-6}\right)\end{array}$ & $\begin{array}{c}0.325 \\
(0.0008)\end{array}$ & $\begin{array}{l}0.06 \\
(0.59)\end{array}$ \\
\hline FA & $\begin{array}{l}0.076 \\
(0.45)\end{array}$ & $\begin{array}{l}0.112 \\
(0.26)\end{array}$ & $\begin{array}{l}0.092 \\
(0.36)\end{array}$ & $\begin{array}{l}0.045 \\
(0.66)\end{array}$ & $\begin{array}{l}-0.004 \\
(0.97)\end{array}$ \\
\hline MD & $\begin{array}{l}0.172 \\
(0.08)\end{array}$ & $\begin{array}{l}0.150 \\
(0.13)\end{array}$ & $\begin{array}{c}0.356 \\
(0.0003)\end{array}$ & $\begin{array}{l}0.192 \\
(0.05)\end{array}$ & $\begin{array}{l}0.06 \\
(0.58)\end{array}$ \\
\hline$A D$ & $\begin{array}{l}0.231 \\
(0.02)\end{array}$ & $\begin{array}{r}0.196 \\
(0.048)\end{array}$ & $\begin{array}{c}0.433 \\
\left(6 \times 10^{-6}\right)\end{array}$ & $\begin{array}{l}0.225 \\
(0.02)\end{array}$ & $\begin{array}{l}0.046 \\
(0.65)\end{array}$ \\
\hline $\mathrm{RD}$ & $\begin{array}{l}0.132 \\
(0.19)\end{array}$ & $\begin{array}{l}0.117 \\
(0.24)\end{array}$ & $\begin{array}{r}0.299 \\
(0.002)\end{array}$ & $\begin{array}{l}0.165 \\
(0.10)\end{array}$ & $\begin{array}{l}0.06 \\
(0.57)\end{array}$ \\
\hline
\end{tabular}

The EDSS adjusted for age and LV provides a means to quantify the direct effects of disease progression without the confounding effects of natural aging and whole-brain LV. Statistically significant values $(p<0.05)$ are in bold. MD $A D, R D=$ mean, axial, and radial tensor diffusivities, respectively.

$(0.003 \pm 001) \times$ Age; $r=-0.297 ; p=0.002], \mathrm{DD}[\mathrm{NTV}(\mathrm{DD}$ in years $)=(0.962 \pm 0.016)-(0.004 \pm 0.001) \times \mathrm{DD} ; r=-0.364$; $\left.p=1 \times 10^{-4}\right]$, LV (Fig. $2 E$ ), and EDSS (Fig. $2 F$ ). In addition, Table 2 provides also the EDSS vs NTV correlation upon adjusting for age- and whole-brain lesion volume. Note that the correlation of EDSS with NTV adjusted for age and LV was statistically significant $(r=-0.20 ; p=0.04$; Fig. $2 F)$.

\section{Discussion}

We presented for the first time in vivo the age-expected thalamic volumetry, and corresponding T2 relaxation time, and DTI metrics on a relatively large cohort of MS patients and healthy controls across the active human lifespan. We also provided cross-sectional qMRI metrics of the thalami on patients as function of disease duration, whole-brain lesion volume, and disability.

A major finding of this report is that thalamic volume loss in MS patients correlated with disability after adjusting for natural aging and whole-brain lesion volume. Accounting for age is important as thalamic volume and corresponding qMRI metrics also depended on age. The relationship between age and qMRI metrics is not necessarily constant or linear as commonly assumed. Incorporating large cohorts of healthy controls and patients enabled the quantification of development and early and late aging effects on the disease-driven tissue loss.

Our results on the normative thalamic volumetry or macrostructure across the lifespan consolidate several past and recent reports (Pieperhoff et al., 2008) on the development (Ostby et al., 2009) and aging of this important territory using similar methods applied on multicenter cohorts (Walhovd et al., 2011). The thalamic volume evolution and corresponding microstructural changes across the lifespan indexed by T2 relaxation time, diffusion anisotropy, and mean diffusivity mark the changes in thalamic connections, subcortical, and cortical domains (Sowell et al., 2003) that are subserved by this territory (Behrens et al., 2003).

Our findings in regards to decreased NTV in MS patients compared with healthy adults consolidate previous reports (Houtchens et al., 2007; Tao et al., 2009; Pellicano et al., 2010; Rocca et al., 2010).

Our results on the lesion distribution and in particular minimal thalamic lesions are consistent with several histopathological (Brownell and Hughes, 1962) and noninvasive neuroimaging
(Bagnato et al., 2006; Derache et al., 2006; Ceccarelli et al., 2008; Tovar-Moll et al., 2009; Pellicano et al., 2010) reports. Reduced thalamic lesion frequency may be explained by the high baseline or normative arterial perfusion of the thalamus and other deep gray matter structures such as the putamen (Heiss et al., 2004) compared to adjacent white matter (Varga et al., 2009).

The elevated thalamic T2 relaxation average values and increased mean diffusivity measurements reflect reduced microstructural organization (Beaulieu, 2002) and may be related to the pathological hallmarks of MS, which include edema, neuroaxonal loss, gliosis, and demyelination (Cifelli et al., 2002; Vercellino et al., 2009).

In the absence of visible thalamic lesions triggered by any injury mechanism, the loss of thalamic macrostructural volume and microstructural integrity evidenced by increased diffusivity and increased T2 relaxation time may then be related to its connections to the cortex (Behrens et al., 2003) and other brain regions through white matter pathways (Henry et al., 2009). In our analyses, we covaried the effects of age and whole-brain lesion volume, and yet thalamic volume loss predicted disability, hinting at a neurodegenerative element that is not explained by inflammatory lesions (Cifelli et al., 2002; Lassmann, 2007; Chard and Miller, 2009; Antulov et al., 2011).

The normal-appearing or lesion-free thalami volumetry in MS patients seem to be smaller than controls at all ages (Fig. 2A), hinting at early neurodegenerative pathology. Extending the MS population to include younger MS patients would provide additional clues to the evolution of this challenging disease.

In conclusion, using a multimodal qMRI approach applied to the thalami and accounting for lesion distribution, late development, and natural aging, we were able to demonstrate that MS pathology has a neurodegenerative component independent from lesions. Our data on the thalamus should help in the future design of clinical trials that incorporate patients with wide age span that include children.

\section{References}

Antulov R, Carone DA, Bruce J, Yella V, Dwyer MG, Tjoa CW, Benedict RH, Zivadinov R (2011) Regionally distinct white matter lesions do not contribute to regional gray matter atrophy in patients with multiple sclerosis. J Neuroimaging 21:210-218.

Aubert-Broche B, Fonov V, Ghassemi R, Narayanan S, Arnold DL, Banwell B, Sled JG, Collins DL (2011) Regional brain atrophy in children with multiple sclerosis. Neuroimage 58:409-415.

Bagnato F, Butman JA, Gupta S, Calabrese M, Pezawas L, Ohayon JM, TovarMoll F, Riva M, Cao MM, Talagala SL, McFarland HF (2006) In vivo detection of cortical plaques by MR imaging in patients with multiple sclerosis. AJNR Am J Neuroradiol 27:2161-2167.

Beaulieu C (2002) The basis of anisotropic water diffusion in the nervous system - a technical review. NMR Biomed 15:435-455.

Behrens TE, Johansen-Berg H, Woolrich MW, Smith SM, Wheeler-Kingshott CA, Boulby PA, Barker GJ, Sillery EL, Sheehan K, Ciccarelli O, Thompson AJ, Brady JM, Matthews PM (2003) Non-invasive mapping of connections between human thalamus and cortex using diffusion imaging. Nat Neurosci 6:750-757.

Blinkenberg M, Rune K, Jensen CV, Ravnborg M, Kyllingsbaek S, Holm S, Paulson OB, Sørensen PS (2000) Cortical cerebral metabolism correlates with MRI lesion load and cognitive dysfunction in MS. Neurology 54:558-564.

Brett M, Leff AP, Rorden C, Ashburner J (2001) Spatial normalization of brain images with focal lesions using cost function masking. Neuroimage 14:486-500.

Brownell B, Hughes JT (1962) The distribution of plaques in the cerebrum in multiple sclerosis. J Neurol Neurosurg Psychiatry 25;315-320.

Ceccarelli A, Rocca MA, Pagani E, Colombo B, Martinelli V, Comi G, Filippi M (2008) A voxel-based morphometry study of grey matter loss in MS patients with different clinical phenotypes. Neuroimage 42:315-322. 
Chard D, Miller D (2009) Is multiple sclerosis a generalized disease of the central nervous system? An MRI perspective. Curr Opin Neurol 22:214-218.

Cifelli A, Arridge M, Jezzard P, Esiri MM, Palace J, Matthews PM (2002) Thalamic neurodegeneration in multiple sclerosis. Ann Neurol 52:650-653.

Courchesne E, Chisum HJ, Townsend J, Cowles A, Covington J, Egaas B, Harwood M, Hinds S, Press GA (2000) Normal brain development and aging: quantitative analysis at in vivo MR imaging in healthy volunteers. Radiology 216:672-682.

Derache N, Marié RM, Constans JM, Defer GL (2006) Reduced thalamic and cerebellar rest metabolism in relapsing-remitting multiple sclerosis, a positron emission tomography study: correlations to lesion load. J Neurol Sci 245:103-109.

Derakhshan M, Caramanos Z, Giacomini PS, Narayanan S, Maranzano J, Francis SJ, Arnold DL, Collins DL (2010) Evaluation of automated techniques for the quantification of grey matter atrophy in patients with multiple sclerosis. Neuroimage 52:1261-1267.

Desikan RS, Ségonne F, Fischl B, Quinn BT, Dickerson BC, Blacker D, Buckner RL, Dale AM, Maguire RP, Hyman BT, Albert MS, Killiany RJ (2006) An automated labeling system for subdividing the human cerebral cortex on MRI scans into gyral based regions of interest. Neuroimage 31:968-980.

Fischl B, Salat DH, Busa E, Albert M, Dieterich M, Haselgrove C, van der Kouwe A, Killiany R, Kennedy D, Klaveness S, Montillo A, Makris N, Rosen B, Dale AM (2002) Whole brain segmentation: automated labeling of neuroanatomical structures in the human brain. Neuron 33:341-355.

Fjell AM, Westlye LT, Amlien I, Espeseth T, Reinvang I, Raz N, Agartz I, Salat DH, Greve DN, Fischl B, Dale AM, Walhovd KB (2009) Minute effects of sex on the aging brain: a multisample magnetic resonance imaging study of healthy aging and Alzheimer's disease. J Neurosci 29:8774-8783.

Ge Y, Jensen JH, Lu H, Helpern JA, Miles L, Inglese M, Babb JS, Herbert J, Grossman RI (2007) Quantitative assessment of iron accumulation in the deep gray matter of multiple sclerosis by magnetic field correlation imaging. AJNR Am J Neuroradiol 28:1639-1644.

Geurts JJ, Reuling IE, Vrenken H, Uitdehaag BM, Polman CH, Castelijns JA, Barkhof F, Pouwels PJ (2006) MR spectroscopic evidence for thalamic and hippocampal, but not cortical, damage in multiple sclerosis. Magn Reson Med 55:478-483.

Hasan KM (2007) A framework for quality control and parameter optimization in diffusion tensor imaging: theoretical analysis and validation. Magn Reson Imaging 25:1196-1202.

Hasan KM, Frye RE (2011) Diffusion tensor-based regional gray matter tissue segmentation using the international consortium for brain mapping atlases. Hum Brain Mapp 32:107-117.

Hasan KM, Narayana PA (2003) Computation of the fractional anisotropy and mean diffusivity maps without tensor decoding and diagonalization: theoretical analysis and validation. Magn Reson Med 50:589-598.

Hasan KM, Sankar A, Halphen C, Kramer LA, Brandt ME, Juranek J, Cirino PT, Fletcher JM, Papanicolaou AC, Ewing-Cobbs L (2007) Development and organization of the human brain tissue compartments across the lifespan using diffusion tensor imaging. Neuroreport 18:1735-1739.

Hasan KM, Halphen C, Kamali A, Nelson FM, Wolinsky JS, Narayana PA (2009) Caudate nuclei volume, diffusion tensor metrics, and T(2) relaxation in healthy adults and relapsing-remitting multiple sclerosis patients: implications for understanding gray matter degeneration. J Magn Reson Imaging 29:70-77.

Hasan KM, Kamali A, Abid H, Kramer LA, Fletcher JM, Ewing-Cobbs L (2010a) Quantification of the spatiotemporal microstructural organization of the human brain association, projection and commissural pathways across the lifespan using diffusion tensor tractography. Brain Struct Funct 214:361-373.

Hasan KM, Walimuni IS, Kramer LA, Frye RE (2010b) Human brain atlasbased volumetry and relaxometry: application to healthy development and natural aging. Magn Reson Med 64:1382-1389.

Hasan KM, Walimuni IS, Kramer LA, Narayana PA (2011a) Human brain iron mapping using atlas-based T(2) relaxometry. Magn Reson Med. Advance online publication. doi:10.1002/mrm.23054.

Hasan KM, Walimuni IS, Kramer LA, Ewing-Cobbs L (2011b) Atlas-based T2 relaxometry of the developing child brain: serial and cross-sectional analysis. Proceedings of the 19th Annual Meeting and Exhibition of In- ternational Society for Magnetic Resonance in Medicine, May, Montréal, Québec, Canada; \#4328.

Hasan KM, Walimuni IS, Humaira A, Datta S, Wolinsky JS, Narayana PA (2011c) Human brain atlas-based multimodal MRI analysis of volumetry, diffusimetry, relaxometry and lesion distribution in multiple sclerosis patients and healthy adult controls: implications for understanding the pathogenesis of multiple sclerosis and consolidation of quantitative MRI results in MS. J Neurol Sci. doi:10.1016/j.jns.2011.09.015.

Hasan KM, Walimuni IS, Abid H, Datta S, Nelson F, Wolinsky JS, Narayana PA (2011d) Brain atlas-based lesion spatial distribution and modeling of Wallerian degeneration in multiple sclerosis. Proceedings of the 19th Annual Meeting and Exhibition of International Society for Magnetic Resonance in Medicine, May, Montréal, Québec, Canada; \#4086.

Heiss WD, Habedank B, Klein JC, Herholz K, Wienhard K, Lenox M, Nutt R (2004) Metabolic rates in small brain nuclei determined by highresolution PET. J Nucl Med 45:1811-1815.

Henry RG, Shieh M, Amirbekian B, Chung S, Okuda DT, Pelletier D (2009) Connecting white matter injury and thalamic atrophy in clinically isolated syndromes. J Neurol Sci 282:61-66.

Houtchens MK, Benedict RH, Killiany R, Sharma J, Jaisani Z, Singh B, Weinstock-Guttman B, Guttmann CR, Bakshi R (2007) Thalamic atrophy and cognition in multiple sclerosis. Neurology 69:1213-1223.

Kochunov P, Williamson DE, Lancaster J, Fox P, Cornell J, Blangero J, Glahn DC (2010) Fractional anisotropy of water diffusion in cerebral white matter across the lifespan. Neurobiol Aging. Retrieved October 20, 2011. doi:10.1016/j.neurobiolaging.2010.01.014.

Lassmann H (2007) Multiple sclerosis: is there neurodegeneration independent from inflammation? J Neurol Sci 259:3-6.

Lebel C, Walker L, Leemans A, Phillips L, Beaulieu C (2008) Microstructural maturation of the human brain from childhood to adulthood. Neuroimage 40:1044-1055.

Leppert IR, Almli CR, McKinstry RC, Mulkern RV, Pierpaoli C, Rivkin MJ, Pike GB (2009) T(2) relaxometry of normal pediatric brain development. National Institutes of Health (NIH) MRI study of normal brain development. J Magn Reson Imaging 29:258-267.

Mesaros S, Rocca MA, Absinta M, Ghezzi A, Milani N, Moiola L, Veggiotti P, Comi G, Filippi M (2008) Evidence of thalamic gray matter loss in pediatric multiple sclerosis. Neurology 70:1107-1112.

Narayanan S, Fu L, Pioro E, De Stefano N, Collins DL, Francis GS, Antel JP, Matthews PM, Arnold DL (1997) Imaging of axonal damage in multiple sclerosis: spatial distribution of magnetic resonance imaging lesions. Ann Neurol 41:385-391.

Niepel G, Tench ChR, Morgan PS, Evangelou N, Auer DP, Constantinescu CS (2006) Deep gray matter and fatigue in MS: a T1 relaxation time study. J Neurol 253:896-902.

Ostby Y, Tamnes CK, Fjell AM, Westlye LT, Due-Tønnessen P, Walhovd KB (2009) Heterogeneity in subcortical brain development: a structural magnetic resonance imaging study of brain maturation from 8 to 30 years. J Neurosci 29:11772-11782.

Pellicano C, Gallo A, Li X, Ikonomidou VN, Evangelou IE, Ohayon JM, Stern SK, Ehrmantraut M, Cantor F, McFarland HF, Bagnato F (2010) Relationship of cortical atrophy to fatigue in patients with multiple sclerosis. Arch Neurol 67:447-453

Pieperhoff P, Hömke L, Schneider F, Habel U, Shah NJ, Zilles K, Amunts K (2008) Deformation field morphometry reveals age-related structural differences between the brains of adults up to 51 years. J Neurosci $28: 828-842$.

Pierpaoli C, Jezzard P, Basser PJ, Barnett A, Di Chiro G (1996) Diffusion tensor MR imaging of the human brain. Radiology 201:637-648.

Ramasamy DP, Benedict RH, Cox JL, Fritz D, Abdelrahman N, Hussein S, Minagar A, Dwyer MG, Zivadinov R (2009) Extent of cerebellum, subcortical and cortical atrophy in patients with MS: a case-control study. J Neurol Sci 282:47-54.

Rocca MA, Mesaros S, Pagani E, Sormani MP, Comi G, Filippi M (2010) Thalamic damage and long-term progression of disability in multiple sclerosis. Radiology 257:463-469.

Sailer M, Fischl B, Salat D, Tempelmann C, Schönfeld MA, Busa E, Bodammer N, Heinze HJ, Dale A (2003) Focal thinning of the cerebral cortex in multiple sclerosis. Brain 126:1734-1744.

Saito N, Sakai O, Ozonoff A, Jara H (2009) Relaxo-volumetric multispectral quantitative magnetic resonance imaging of the brain over the human 
lifespan: global and regional aging patterns. Magn Reson Imaging 27:895-906.

Sajja BR, Datta S, He R, Mehta M, Gupta RK, Wolinsky JS, Narayana PA (2006) Unified approach for multiple sclerosis lesion segmentation on brain MRI. Ann Biomed Eng 34:142-151.

Sepulcre J, Goñi J, Masdeu JC, Bejarano B, Vélez de Mendizábal N, Toledo JB, Villoslada P (2009) Contribution of white matter lesions to gray matter atrophy in multiple sclerosis: evidence from voxel-based analysis of T1 lesions in the visual pathway. Arch Neurol 66:173-179.

Smith SM (2002) Fast robust automated brain extraction. Hum Brain Mapp 17:143-155.

Sowell ER, Peterson BS, Thompson PM, Welcome SE, Henkenius AL, Toga AW (2003) Mapping cortical change across the human life span. Nat Neurosci 6:309-315.

Tao G, Datta S, He R, Nelson F, Wolinsky JS, Narayana PA (2009) Deep gray matter atrophy in multiple sclerosis: a tensor based morphometry. J Neurol Sci 282:39-46.

Tovar-Moll F, Evangelou IE, Chiu AW, Richert ND, Ostuni JL, Ohayon JM, Auh S, Ehrmantraut M, Talagala SL, McFarland HF, Bagnato F (2009)
Thalamic involvement and its impact on clinical disability in patients with multiple sclerosis: a diffusion tensor imaging study at 3T. AJNR Am J Neuroradiol 30:1380-1386.

Varga AW, Johnson G, Babb JS, Herbert J, Grossman RI, Inglese M (2009) White matter hemodynamic abnormalities precede sub-cortical gray matter changes in multiple sclerosis. J Neurol Sci 282:28-33.

Vercellino M, Masera S, Lorenzatti M, Condello C, Merola A, Mattioda A, Tribolo A, Capello E, Mancardi GL, Mutani R, Giordana MT, Cavalla P (2009) Demyelination, inflammation, and neurodegeneration in multiple sclerosis deep gray matter. J Neuropathol Exp Neurol 68:489-502.

Walhovd KB, Westlye LT, Amlien I, Espeseth T, Reinvang I, Raz N, Agartz I, Salat DH, Greve DN, Fischl B, Dale AM, Fjell AM (2011) Consistent neuroanatomical age-related volume differences across multiple samples. Neurobiol Aging 32:916-932.

Walimuni IS, Hasan KM (2011) Atlas-based investigation of human brain tissue microstructural spatial heterogeneity and interplay between transverse relaxation time and radial diffusivity. Neuroimage 57:1402-1410. 